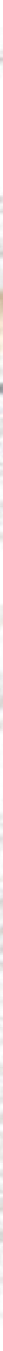

El parque como dispositivo de cohesión social y territorial del sur de Sevilla. Fuente: FACTOR-IA 


\section{Ensayo sobre Arquitectura, cohesión social e identidad. Otra razón urbana de Sevilla}

Félix de la Iglesia Salgado, Miguel Ángel Rojas Rodríguez, José Antonio Ruiz Villén, FACTOR-IA

\section{Resumen}

El presente ensayo reflexiona sobre determinadas estrategias urbanas que, volcadas sobre nuevas situaciones resultado del cambio cualitativo y cuantitativo que se produce en nuestras ciudades, proponen una nueva urbanidad; una búsqueda, a partir de la experiencia propia en torno al sur de Sevilla, sobre el control de los nuevos lugares y formas de habitabilidad que se hacen visibles como partes de una red de relaciones territoriales complejas que se incorporan al imaginario colectivo. Ello desde una noción de habitabilidad no destructora del entorno y la alteridad que hace necesario un ajuste entre unas condiciones materiales y culturales distintas y la generación de modos de vida consecuentes. Así, se exploran nuevas lecturas del espacio público, al tiempo que diseñan escenarios y paisajes urbanos más participados por la ciudadanía, en una nueva valoración espacio-temporal y formando parte de un paisaje cultural alternativo. Se abren y explicitan procesos de desvelamientos y configuración de bandas de actividad que favorezcan la cohesión urbana y territorial, ensayando, igualmente, lenguajes acordes a las futuras políticas de reinserción social en relación con la cultura urbana actual.

\section{Palabras clave}

Barriadas / Identidad / Espacio público / Espacios de sociabilidad / Guadaira, río / Habitabilidad / Paisaje urbano / Puesta en valor / Sevilla / Urbanismo 


\section{INTRODUCCIÓN}

\section{Aproximación a la nueva Sevilla: de la ciudad-centro al territorio-malla}

El papel de centralidad que Sevilla viene desempeñado como capital andaluza desde las últimas décadas del pasado siglo ha hecho que en muy breve espacio de tiempo pase de ser una ciudad en gran medida ensimismada, atenta y ordenada en consideración a su centro histórico, a extender su mirada a un territorio complejo que se incorpora al imaginario colectivo. Primero, introduciendo la bipolaridad con la aparición de un nuevo centro económico, comercial y administrativo en su sector oriental y, posteriormente, formando parte de una red de relaciones territoriales en la que el conjunto de poblaciones periféricas se incorporan al desarrollo y determinaciones de una vida ciudadana que se sabe referenciada en su área metropolitana.

Como consecuencia de este salto dimensional sufrido en tan pocos años, la noción misma de habitabilidad se ha transformado, haciendo necesario producir un ajuste entre unas condiciones materiales y culturales distintas y las oportunidades para generar modos de vida acordes con ellas.

Con el Plan General de Ordenación Urbanística de la ciudad se han planteado nuevas lecturas del espacio público -cultivando y proponiendo comportamientos no destructores del entorno y la alteridad- y diseñado escenarios y paisajes urbanos más participados. Se ejemplifican, aqui y ahora, determinados criterios y ensayos de espacialización que, con el horizonte de la cohesión social y urbana para la nueva escala de ciudad, se han puesto en marcha a partir del Parque sobre el Antiguo Cauce del Río Guadaira, localizado en la región sur del municipio.

Esta reflexión en torno a la búsqueda de nuevos lugares y formas de habitabilidad pretende, como investigación aplicada desde este ámbito de Sevilla, indagar en un territorio complejo, en un distinto paisaje cultural disociado en parte de la imagen más convencional de la ciudad y donde no siempre es viable una práctica ciudadana completa y plural. Un apunte que se instala en una consideración habitativa de presente, en la que la casa, el barrio, la ciudad y el territorio -leídos desde la ecología, el patrimonio, la ética o la imagen- forman parte del mismo soporte.

La lectura y puesta en valor del conjunto de comportamientos, materiales y elementos presentes en el sitio -sociológicos, simbólicos, paisajísticos, edificatorios, etc.- ha permitido vislumbrar tanto la conformación de nuevos espacios de relación entre lo doméstico y la secuencia de espacios semipúblicos y públicos que cubren las necesidades que esta sociedad demanda, como la incorporación de nuevas actividades y ámbitos de participación que cohesionan lugares y ciudadanos.

Así, para producir esta acción y descubrir aquellos espacios donde ensayar nuevas fórmulas de relación, se ha tomado como referen- cia el conjunto del área meridional de la ciudad: un ámbito extenso y desconocido en muchos casos, marcado a un mismo tiempo por lugares de excelencia, que van desde los productivos de la zona portuaria hasta los naturales del entorno del río Guadaira, o por situaciones de extrema marginalidad, como la barriada Martínez Montañés en el Polígono Sur. Un denso y diverso territorio que ha llevado, metodológicamente, a una búsqueda sobre el habitar desde la ecología, lo social o el patrimonio, extendiendo el lugar de la casa a otros ámbitos donde vivienda y espacio cívico se funden en nuevas consideraciones derivadas de su puesta en uso por la ciudadanía. Todo ello, como propone Manuel Delgado a propósito del grupo Stalker, con "la exploración de los itinerarios, preferentemente por espacios ambiguos y desterritorializados, como formas de localización de 'territori attuali', interpretando lo actual en el sentido que propone Foucault no de aquello que somos, sino sobre todo de aquello en lo que nos convertimos, lo que estamos a punto de ser, es decir, lo otro, nuestro devenir otro. La actividad de Stalker consiste en transitar entre lo que es seguro y cotidiano y lo que es incierto, lo que está aún por descubrir, generando "una sensación de desazón, un estado de aprehensión que conduce a una intensificación de las capacidades perceptivas; de este modo, el espacio asume un sentido; por doquier, la posibilidad de un descubrimiento, el miedo a un encuentro no deseado" (DELGADO, 2003: 130).

Ello, partícipes de un compromiso que se hace necesario en una doble dirección: la de quienes, como agentes, promueven y diseñan los nuevos espacios habitables; y la de los individuos, a través de su participación en los procesos de construcción de ciudad.

\section{Otras urbanidades, compromisos y procedimientos}

Nos dice Armando Silva: "En el contexto actual se produce un desplazamiento en la identidad del sujeto que protagoniza la construcción social. Ya no es la comunidad, sino el individuo; ya no es la masa (el pueblo, la nación, la clase obrera), sino la multitud (concebida desde una dimensión lingüistica como enunciación, o desde una dimensión política, cercana a la perspectiva de Toni Negri, como conjunto de subjetividades autónomas pero interconectadas en red) o el grupo (entendido como proyección de unos intereses colectivos que forman una comunidad social transitoria y trans-urbana). Actualmente, la sociedad está experimentando un profundo proceso de desterritorialización que hace que en la investigación sobre las nuevas realidades urbanas, el foco de atención analítico se desplace desde la arquitectura a las culturas" (SILVA, 2005).

Para la técnica contemporánea de la arquitectura, la "vivienda moderna" -capaz de construir ciudad sin limitaciones- ya no es modelo de referencia suficiente para estas nuevas condiciones; el habitar -como la casa- se extiende a otros acontecimientos, a otros universos y la "casa de todos" pone en crisis muchos de los materiales de proyecto que se disponian a tal fin: construcción de un centro-hogar en torno al que se localizaban sus diversos 


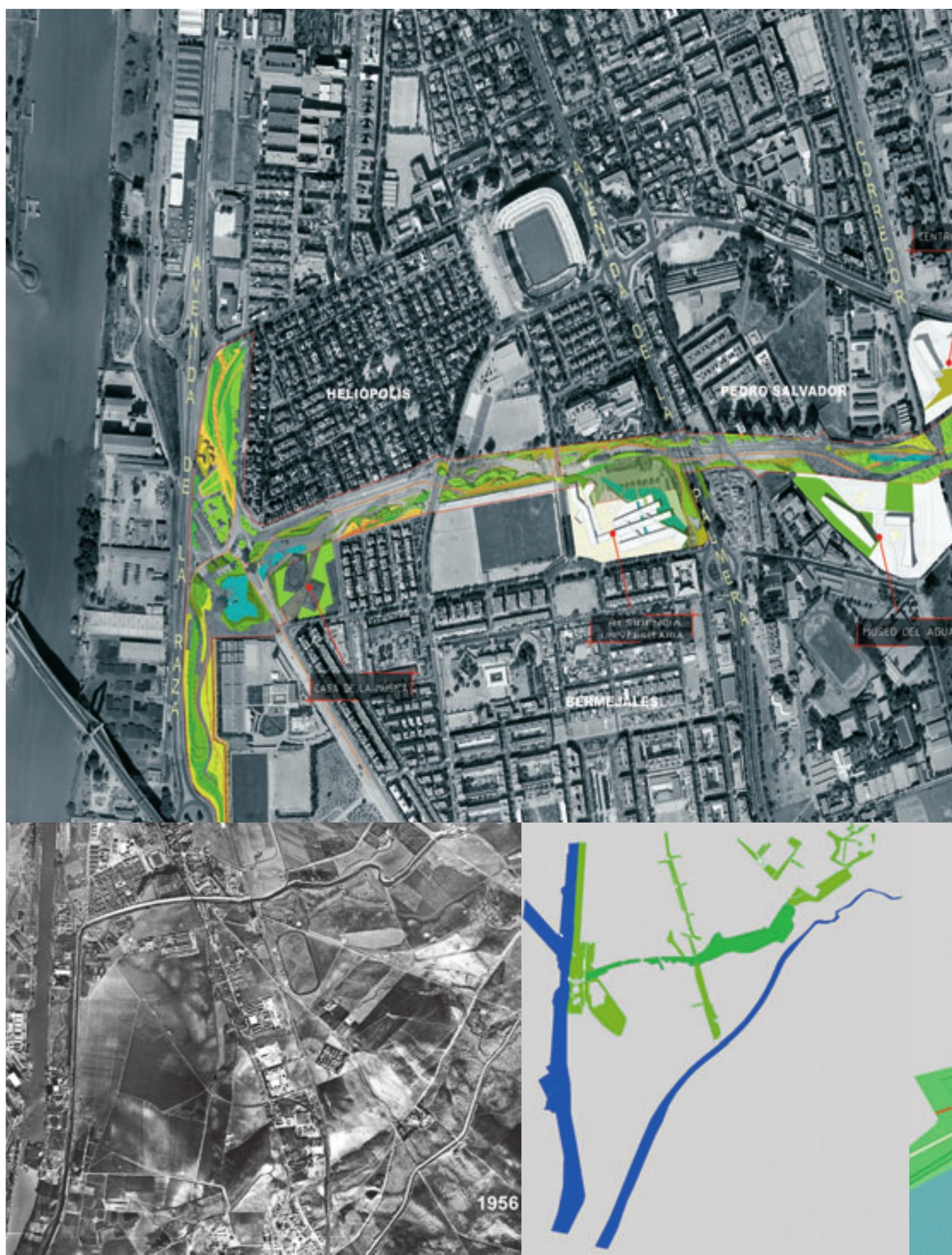




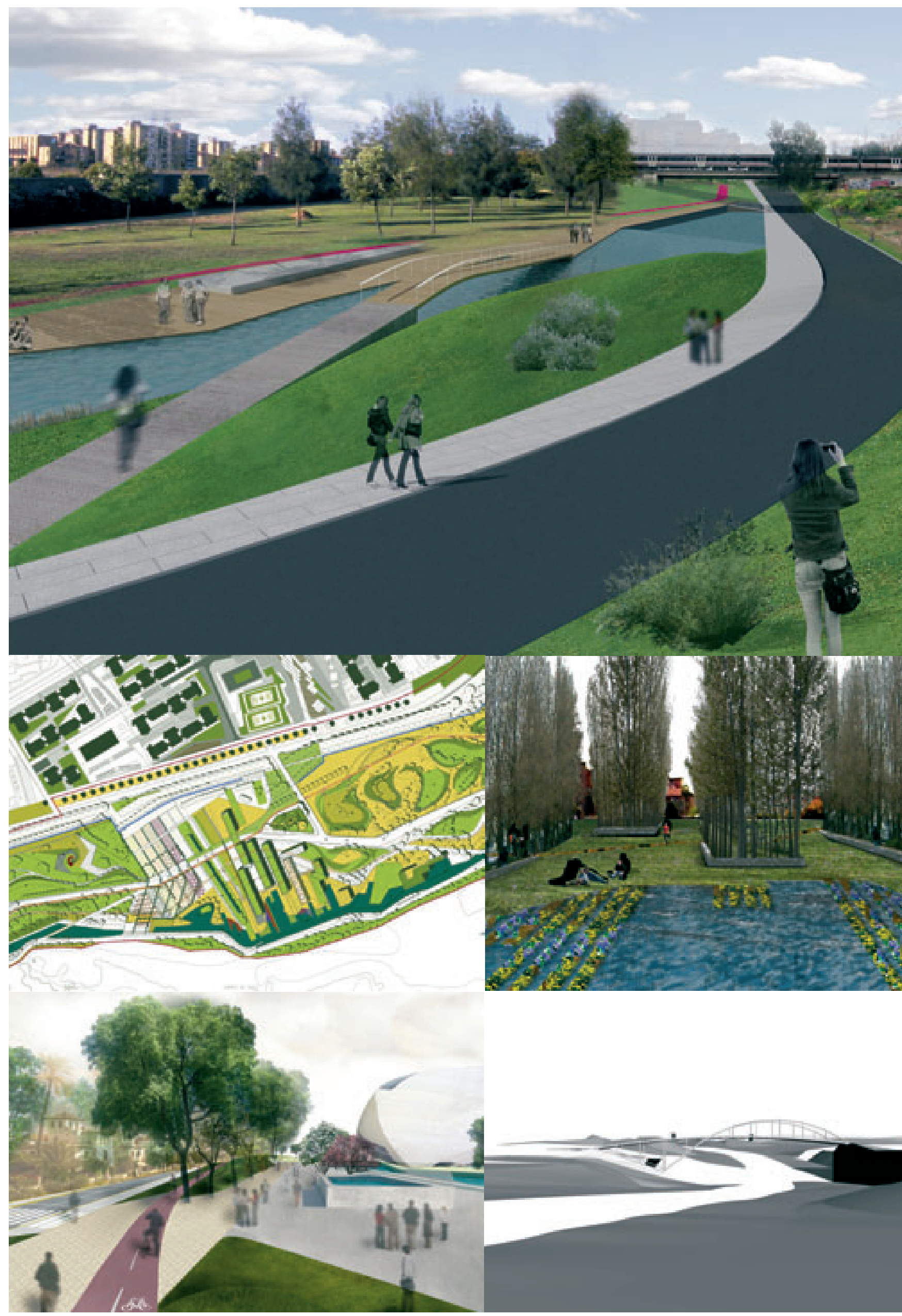

Trazado del Área lagunar y plantaciones de frutales y chopos. Fuente: FACTOR-IA Dotación cultural en Heliópolis. Fuente: FACTOR-IA

Chopera. Fuente: FACTOR-IA

Puente en la avenida de Holanda. Fuente: FACTOR-IA 
Uill

sumatse

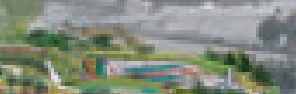

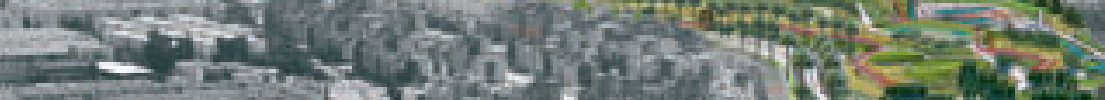

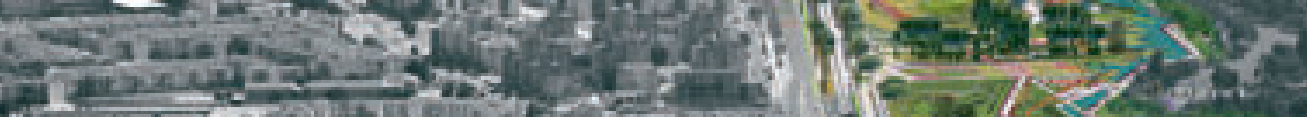

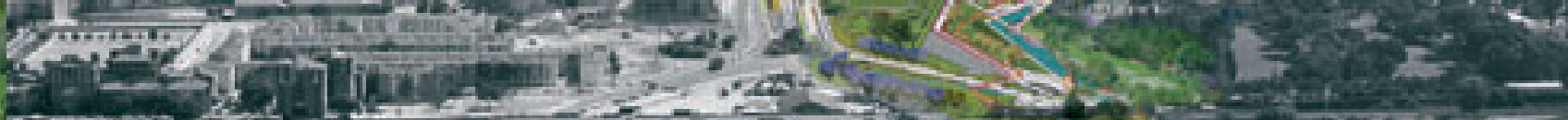

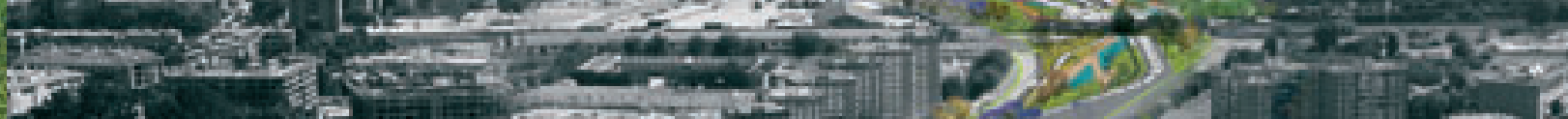
$\operatorname{los}^{2} \mathrm{ag}$ a

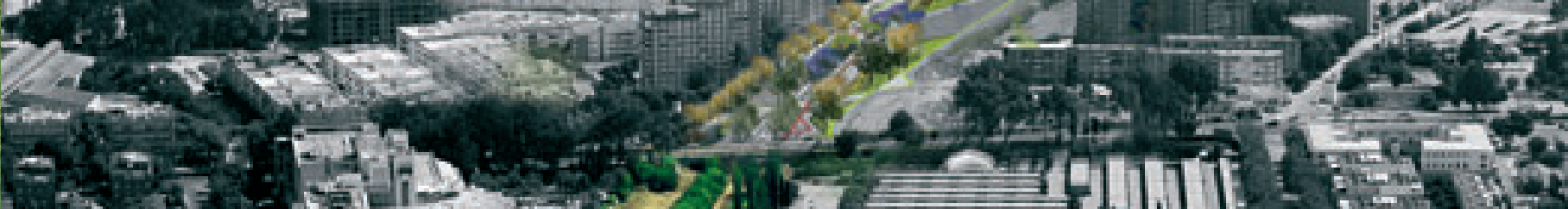

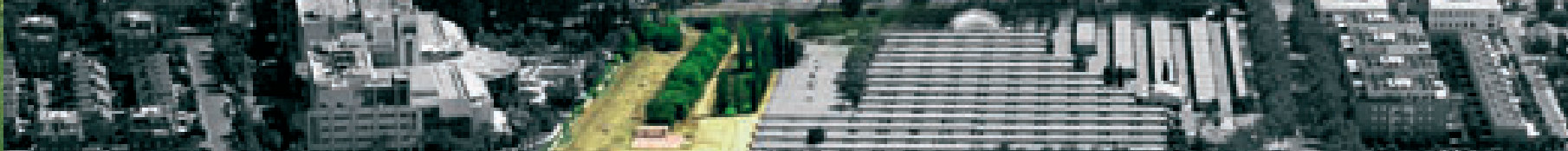

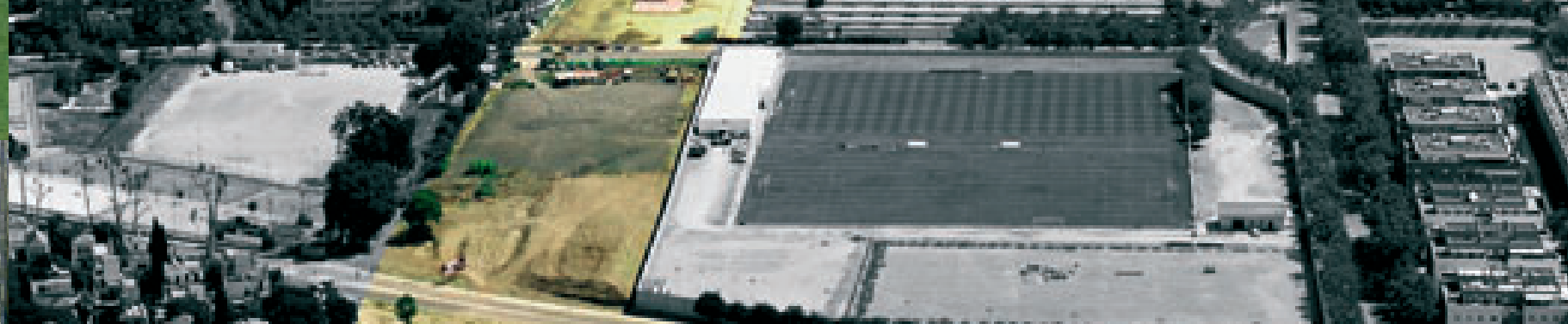

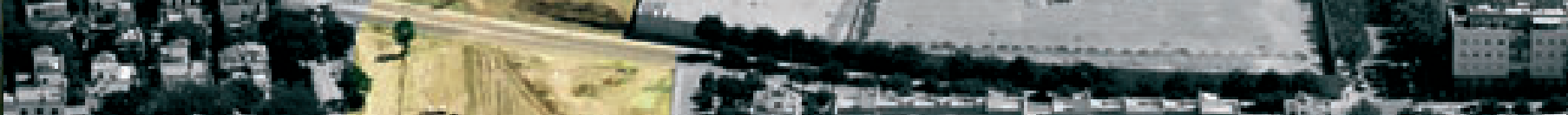

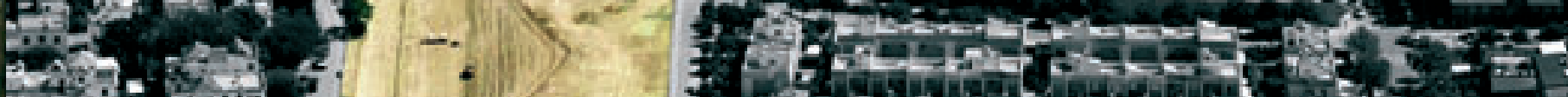

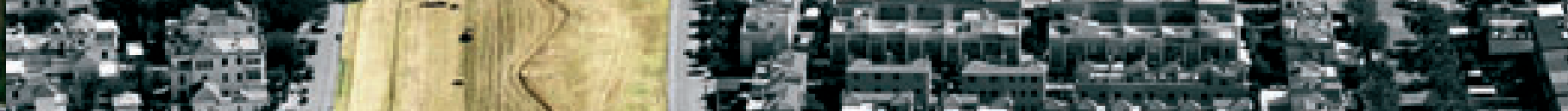

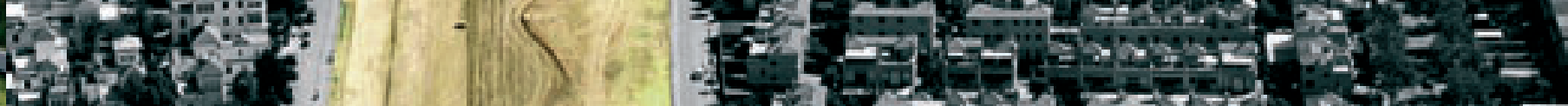
(2) $3 y^{2}$
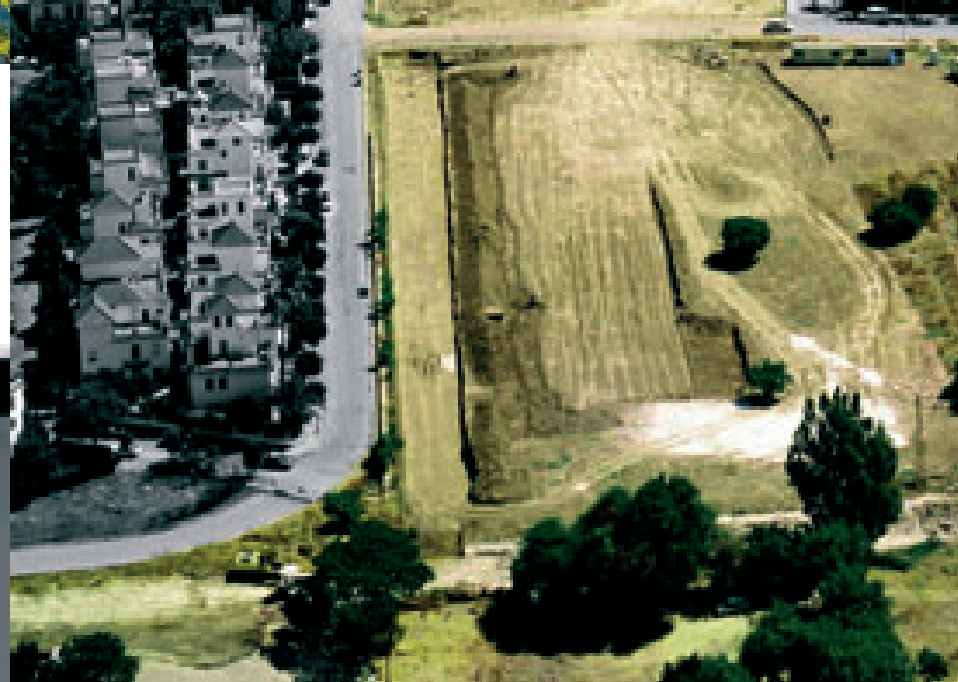
mundos; la jerarquización de espacios ligada inevitablemente a la propia simbolización de la casa; su relación abierta en mayor o menor medida a la ciudad; segregaciones de usos derivados de comportamientos establecidos e incluso promovidos por agentes de la producción; etc.

Hoy se abre un espacio del habitar -extraordinariamente más vasto- donde trazos, fluidos, infiltraciones, decantaciones, materialidades, texturas, comportamientos, virtualidades, etc., hablan a su vez de otras comunidades, de otra memoria e historias $y_{1}$ necesariamente, de otra manera de producirse y manifestarse la arquitectura. Algo especialmente urgente en esos territorios periféricos, donde es preciso entrar con otros procedimientos, con otras escalas y parámetros, buscando situaciones que permitan encontrar nuevas referencias para una habitabilidad plena, consecuente con el sitio y el conjunto de la ciudad.

Como señalamos en la presentación del Foro Barriadas (MORENO; DE LA IGLESIA, 2006)'1, formuladas las barriadas periféricas de nuestras ciudades modernas con una precisa función de habitabilidad primaria, muy próxima a la individualidad doméstica, estos ámbitos urbanos siguen un proceso histórico que va desde ser considerados como ampliación ejemplar de lo que el desarrollo de la ciudad histórica debía ser, a plantearlos como alojamiento de emergencia en respuesta a las condiciones del Estado de Bienestar, cumpliendo con insuficiencia el papel asignado como unidades básicas de articulación entre lo privado y lo público o entre lo doméstico y el consumo que caracteriza la nueva sociedad de final de siglo XX.

Sin embargo, nos encontramos con modos de vida y segmentos sociales marginados en un hábitat segregado, que aportan una cultura de confrontación respecto al proceso de radical homogeneización que vive el resto de la sociedad contemporánea; diversidad y diferencia que inaugura, en algunos casos, otra urbanidad alternativa: emergencia de contraculturas urbanas que abocan a valores positivos, por cuanto constituirian en su marginalidad una respuesta compensatoria a la homogeneidad de modos de vida y valores de la sociedad poscapitalista.

Partiendo de que cada comunidad configura un determinado imaginario, al cual se refiere e instrumenta como medio de relación con su entorno, deberíamos ser conscientes de sus tiempos y espacios, de su toponimia, de su geografía y ocupación. De su patrimonio.

Así, ante la nuevas expectativas creadas en nuestras ciudades, a raíz de una nueva significación urbana y la arquitecturización del entorno, surge una nueva cultura ciudadana -basada en la participación y reconocimiento de nuevos lugares- que tiende a la puesta en valor del espacio cívico y natural como escenario alternativo de vida en donde producir el intercambio y encontrar nuevas identidades.

Esto ha producido un desplazamiento de los intereses y comportamientos urbanos a otras localizaciones más singulares y el des- cubrimiento de nuevas oportunidades en sitios encontrados en su ámbito territorial más cercano. Porque alli convergen muchas miradas, sensibilidades, sociabilidades y políticas que deben dialogar para realizar un discurso lo suficientemente descriptivo y propositivo como para constituirse en modo de visibilidad y medio de respuesta a las problemáticas propias. La proximidad, la comprensión y la colaboración son vectores necesarios para restituir la presencia de estos modos de vida diferentes al conjunto de la ciudadanía; tanto como otro enfoque de la política que asuma que no existen protocolos sociales homogéneos o estados generales, pero si una situación que reclama biopolíticas alternativas.

Se trata de poner en valor el propio lugar en relación con las cosas y personajes encontrados, imaginando acciones que persiguen descubrir enclaves, identificar referentes y construir relaciones de proximidad en lugares de sociabilidad e intercambio; que permiten habilitar escenarios diversos desvelando identidades, huecos donde situarse, trazando líneas de movilidad y conexión, de escalas y contornos alternativos, disponiendo picas en puntos singulares, preparando el suelo con acotaciones distintas para abrirlo a la vida, valorando otros elementos no siempre tenidos por ciudad.

Todo con el objeto de posibilitar e implementar la relación -hoy, bajo mínimos- del sujeto con el lugar, abiertos en gran medida a una distinta actitud cuidadosa y comprometida con el medio ambiente. Y para ello, actuando con los agentes -que promueven y predicen los nuevos espacios de habitabilidad- y con los individuos -a través de su participación en los procesos de transformación-, buscando la revisión del concepto clásico de espacio público para extenderlo a un marco territorial que baraje la máxima expansión del mundo de la casa y dilate las fronteras del habitar como nueva dimensión de la experiencia de los sitios.

Con estas consideraciones, se pretende desvelar la existencia de espacios, de paisajes culturales, donde sea posible la incorporación de nuevas actividades y necesidades que la sociedad demanda, ensayando un proyecto de interpretación y activación de este territorio desde el que plantear dispositivos más libres de aproximación y reorganización de los lugares, para poder posibilitar una habitabilidad plural integrada en el medio y no depredadora de los recursos y energías del sitio. Es lo que conocemos como proyecto patrimonial $^{2}$

\section{Mapa del olvido y de la energía. Aperturas}

Cualquier lenguaje -sea hablado o escrito- está basado en un principio de espaciamiento, se atiene a una espacialidad. En la dialéctica escritura-arquitectura, es decir, en la relación entre habitar-habla, el primero no es el acto del habla sino el del habitar: alguien entra en un territorio, lo circunscribe, lo recorre, lo dimensiona, lo marca significativamente. No hay otro lenguaje, la escritura del habla acompaña lo que son experiencias. Para nosotros, arquitectos, una escritura del habitar deviene en una escritura específica de la arquitectura que explicite la di- 

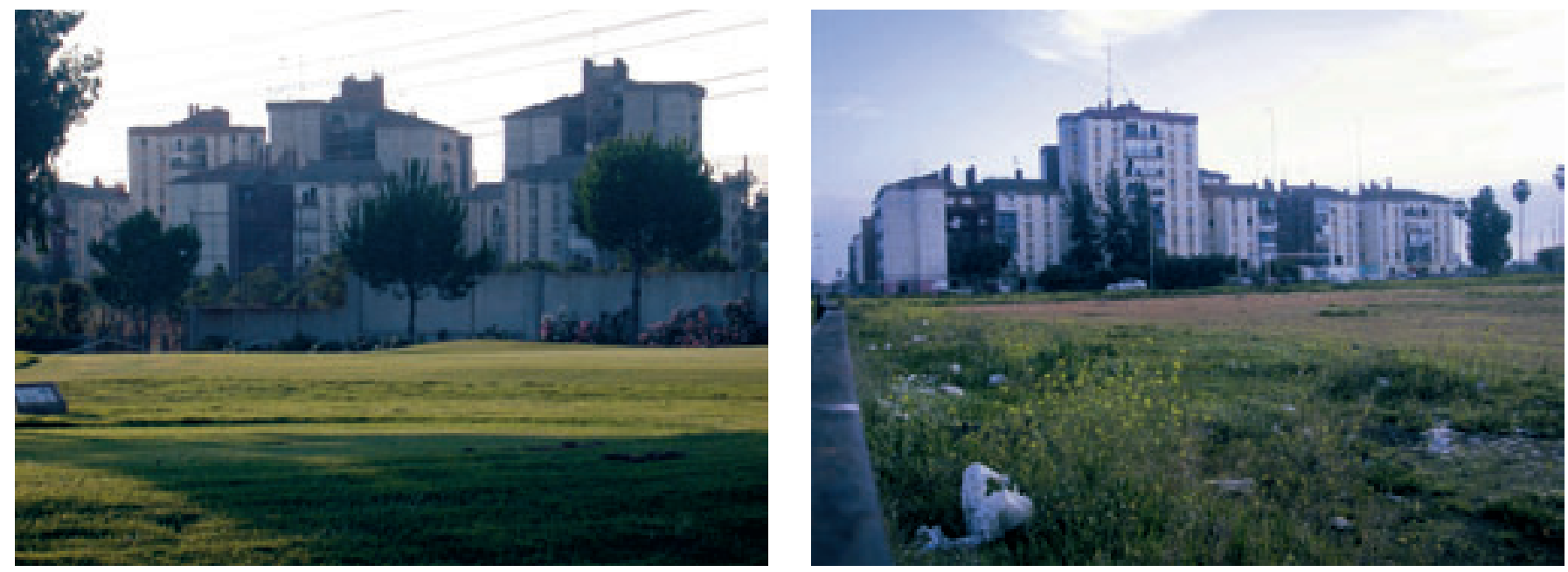

Realidades enfrentadas en el sur de Sevilla: club social y vacío marginal. Fotos: FACTOR-IA
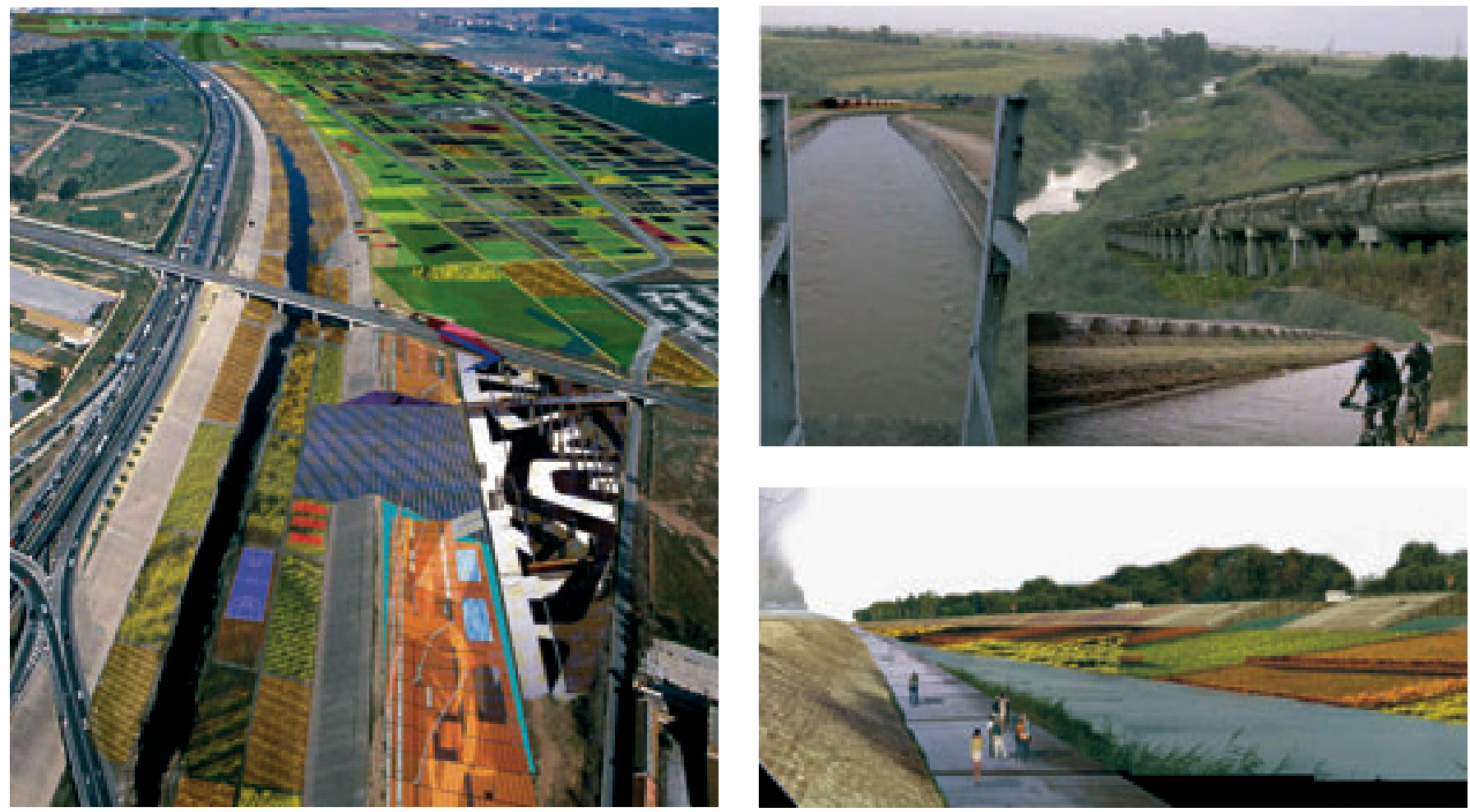

Ámbitos y escenarios ciudadanos localizados en el sur: Foro del río Guadaira. Fuente: FACTOR-IA

mensión habitativa, aún sabiendo que tanto la experiencia del habitar como la experiencia de la lengua están, ahora, mediadas por las imágenes.

Aqui abordamos el estudio de una realidad marcada por lo difuso y el fenómeno de la globalización, donde cualquier elemento es susceptible de incorporarse a su desarrollo y ninguna estructura garantiza la oportunidad de su instalación. Ante esta complejidad, multiplicada exponencialmente por las nuevas estrategias -en especial, las de Comunicación-y por los propios instrumentos de comprensión que las distintas tecnologías (la Arquitectura, la Biología, la Sociología, la Informática, la caótica, etc.) hacen de la misma, lo que necesitamos es un sistema de orientación que ordene nuestros pasos por ella y, consecuentemente, nuevas cartografias de representación y movilidad.
Esto abre el territorio de la arquitectura a ámbitos absolutamente desconocidos para la acción. ¿Cómo actuar en un mundo donde las palabras, como los objetos, flotan y donde sólo se encuentra un principio de orden -espurio y manipulador- en lo mediático? La matriz básica por la que el arquitecto aprehende el mundo tiene algo que ver con la clasificación de las cosas, de los objetos, para permitirle procesar parte de la complejidad a la que se enfrenta. Pero estamos ante una situación de emergencia, de necesidad y despunte, que necesita -porque complejidad es indeterminación y porque las cosas no se juegan en un ajuste de dimensión- de un soporte de mediación capaz y flexible, donde las entidades se yuxtapongan. No puede ser de otra manera.

¿Situación de emergencia? Sí, y para construir esta situación no disponemos de referencias -a partir de una posible continuidad 
con momentos anteriores- ni nos valen los comportamientos reglados generalistas de la razón técnica o el ensimismamiento autista de quien se oculta en la complejidad; pero, sin embargo, sí sabemos de cuántos suelos disponibles existen, cuántos lugares posibles pueden ser vindicados, cuántos sueños de comunidad nos rodean, capaces todos ellos de establecerse entre lo local y lo global si son desvelados, cuánto de pasado sigue siendo aún válido en este presente.

La inevitable incorporación a este medio discontinuo para ofertar nuevos sentidos ha de realizarse por aproximaciones múltiples y colaterales que puedan producir capturas parciales. Y se propondrán estos sentidos en el proceso, poniendo en valor la alteridad de los distintos episodios aparecidos, produciendo nuevas identificaciones marcadas, no por su pertenencia a estructuras -ni por sus estructuras mismas-, sino por la posibilidad de un singular modo de ser habitadas: identificación de ciudades, de barrios, de viviendas, de género, etc., asociadas a procesos de autogestión. Se analizarán los vaivenes entre la identidad y alteridad de los mismos, así como los mecanismos de compensación que se establecen entre ellos.

Porque naturaleza e historia se hacen tierra, se cierran sobre sí mismas trazando un límite plano que impide una participación directa y plena, hemos de marcar cada uno una particular distancia con respecto a la realidad, abriendo un espacio a la interpretación, con la que mantener la identidad del mundo encontrado y del nuestro. Es necesario construir el olvido para sobrevivir, posibilitando que surja el pensamiento no vertido sobre esta realidad por razones inconfesables, la voz callada de quienes la vivieron e hicieron suya; desprendernos de todo lo que nos es dado como regla para que pueda aparecer lo silenciado a los muertos y vencidos.

Un olvido que posibilite la renovación de sus moradores y de nosotros mismos, sabiendo que lo que de siempre pudo parecer de las cosas del lugar entra en relación potencialmente productiva con lo que nos aparece entre las manos como novedad: "sólo por el olvido -señala H. G. Gadamer- obtiene el espíritu la posibilidad de su total renovación, la capacidad de verlo todo con ojos nuevos, de manera que lo que es de antiguo familiar se funda con lo recién percibido en una unidad de muchos estratos" (GADAMER 1984: 45). De esta manera, todo adquiere sentido nuevo al volcarse sobre el conjunto de planos y niveles que, como soporte preparado para su conocimiento y la acción, nos representan este medio en el que deseamos participar activamente.

Todo está disponible para el individuo y para la arquitectura, a la espera de que miremos para elegir e interpretar, para hacerlo nuestro e in-formar. Comencemos sin otro enunciado que el que origina la acción, sin otro argumento que el ponernos en marcha sin otro tiempo que el conjunto de todos los tiempos múltiples que alli se reúnan, sin otros personajes que los que -por nosotrosaparezcan, se manifiesten o desvelen. Un modo de proceder tan familiar como el del niño, que hace confundir realidad y juego para que toda acción y todo gesto se conviertan en señal.

Se trata de ponerse en marcha, sobre un fondo incierto e informe, con un sentido de emergencia, de floración, para sacar a la luz huellas y reflejos de verdad en ese campo infinito de posibilidades. Una puesta en valor distinta: la de nuestro ser en relación con el medio en el que se despliega y su patrimonio como vía de orientación en los lugares, como compromiso cómplice con ellos.

Se trata, en suma, de proponer una figura propia -más allá de la visible o cargada de prejuicios, de la estereotipada o convencional- como registro de la acción, como materialización de una construcción particular e irrepetible, como signo provisional de un encuentro celebrado. Una figura -siempre invención y nueva presentación de la realidad- en donde la acción cobra sentido por ella misma, un soporte donde poner de manifiesto la capacidad y posibilidad que está en las cosas y que las mantiene en vida. Un escenario de posibles sobre el que presentarnos y en el que presentar los objetos, las cosas y los personajes alli encontrados, una vez discriminados en su valor de verdad y significado. Un soporte desde el que convocar los acontecimientos que, en primera instancia, se hacen imprescindibles para su comprensión y la hacen posible en cada instante.

Así, podremos entender lo real como material estructurante y no como fondo donde producir el espectáculo o situar nuestras obsesiones. Con el ensayo como posibilidad y la interpretación como forma, aparecerán instalaciones donde producir demoras, surgirán comportamientos distintos de viejos personajes generados por nuevos impulsos, se manifestarán energías alli presentes que restaurarán la presencia de las cosas.

Una vez formuladas lo que serían las razones, rasgos constitutivos y alcance de una distinta instrumentación de la técnica arquitectónica, en la que el carácter totalizante y abarcativo del orden espacial de la modernidad viene cuestionado y alternativamente sustituido por un empeño en la singularidad y una potenciación de sus posibilidades, se presenta lo que ha sido una experiencia que ahora puede verse como formulación previa de un soporte territorial activo.

\section{LA ACTIVACIÓN DEL TERRITORIO COMO SOPORTE PARA LA GESTIÓN}

\section{Lo local frente a lo global: Sevilla, y en Sevilla, el Sur y el Polígono Sur}

Nos dice Massimo Cacciari: "Interrogarse por la diferencia implica interrogarse por la identidad; maravillarse por lo múltiple inicia el recuerdo de lo Uno. No bastará con conocer la diferencia y analizarla, es necesario preguntarse cómo ha sobrevenido la escisión. (...) Buscar la razón de lo múltiple actual significa recordar el pa- 

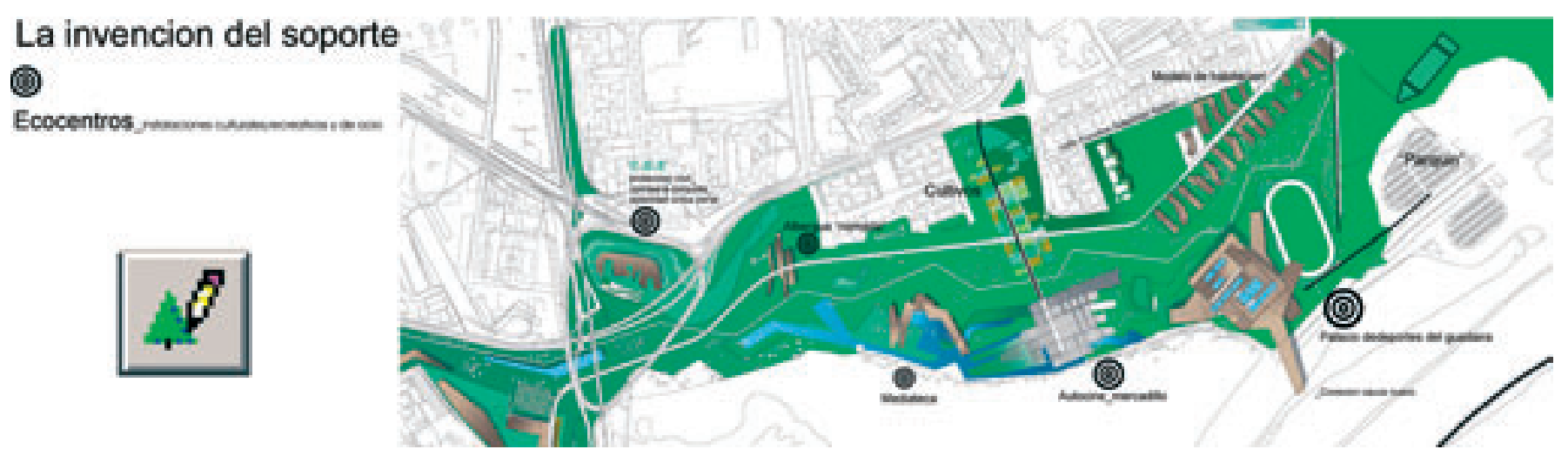

Proceso de generación formal. Fuente: FACTOR-IA

sado. (...) Para curar la ciudad de sus males es necesario conocer su pasado; (...) es necesario conocer su origen verdadero, arriesgarse al viaje por lo no evidente, por aquello de lo que parecía imposible que pudiese haber historia" (CACCIARI, 2000).

El crecimiento de Sevilla en la segunda mitad del pasado siglo, dilatando sus periferias enormemente, la consolidación de Nervión como segundo centro urbano, modificando sustancialmente el carácter del recinto histórico, o el nuevo conjunto de relaciones urbano-territoriales que la aproximan a la escala metropolitana, van a producir un desplazamiento de los intereses y comportamientos ciudadanos a otras localizaciones, descubriendo nuevas oportunidades a los sitios.

Es en el marco del nuevo planeamiento para la ciudad de Sevilla, y dentro de su estrategia de acotación en áreas-estudio-experimentación-propuestas que luego serán integradas en el diseño global del Plan, donde nos situamos. Y es para este cometido, afrontar el sur de la ciudad de manera parcial en un horizonte de totalidad, por lo que se consideran referencias más amplias que den otras pautas para establecer estrategias propias y válidas para toda la ciudad; o se acude a los lugares con otro sentido de la urbanidad, con una cierta indisciplina, partiendo de cero, tanteando y reconociendo el sitio con la esperanza de que es posible recomponerlo globalmente, en sus sentidos más profundos: una propuesta de distintos procesos de desvelamientos que va más allá de cualquier metodología que supere al propio sitio al aplicarse de manera automática.

A poco que levantemos la vista veremos que Sevilla no es sólo la ciudad encerrada en sus murallas hasta fecha bien reciente, ni la ciudad expandida durante el pasado siglo por las exposiciones supranacionales. Es el nodo básico de un sistema territorial de relaciones que sólo es inteligible desde una escala metropolitana, desde la interacción entre los vórtices, sean estos los de las orillas del lago Ligustino o los de esa ciudad policéntrica que coloniza su entorno más inmediato. suaves escarpes del Aljarafe y de los Alcores no son sino las estructuras óseas que enmarcan nuestro centro de atención a la par que lo aproximan extraordinariamente a la desembocadura del Guadalquivir. En apenas 80 kilómetros, el Atlántico: delicias del gran puerto interior. De aquí la condición atlántica de Sevilla, un océano al que se abre el mar interior convertido en marisma, un imaginario que considerar como ideario del sur, una ciudad estuario que revitaliza e introduce nuevas y potentes perspectivas: la ecológica y la patrimonial del valle del Guadalquivir; pero también la viajera, la imaginaria, la de una necesaria apertura a la modernidad.

Un Sur que son varios. Sitios que no se pliegan en el centro histórico -como hasta ahora- y por donde, rota la estructura anular de la ciudad del siglo XX, nos desplegamos por terrenos difusos, por mapas hechos de tejidos hibridos. Un sitio caracterizado por su heterogeneidad, que se modifica cuando se pone en relación con el área metropolitana, en especial con la banda que roza al Aljarafe, construyendo su relación y solape mediante grandes vacios de cercana memoria agrícola y la presencia de las infraestructuras. Y en ellos, el gran Río o los ríos.

Esta visión induce a acciones que buscan aproximaciones y distancias a antiguos y nuevos centros; lo separado en el espacio se une por su puesta en uso, por el carácter de las actividades que se producen en ellos: el ocio y lo verde coligan estructuras dispares; las vecindades se alejan por la existencia de nuevas infraestructuras; se desvelan y posibilitan solapes de situaciones, bolsas indeterminadas, infraestructuras habitadas, paisajes activados, historias encadenadas e identidades; estructuras de participación.

Pero también lugares al margen, vacios de resistencia y organización espacio-temporal de gestión variable, que se conectan con un modelo de ciudad extrovertido más consciente de la naturaleza de cuanto ocurre en ella y de quienes la viven. Así, se podrán dibujar nuevos mapas en los que se disuelvan los límites de suelos calificados, se desdibujen las parcelaciones, aparezcan bandas, filamentos, estrías y flecos de distintos tejidos.

El objetivo sería sustituir un paradigma urbano que pone de manifiesto, desde hace tiempo, disfunciones en el área de estudio y, por 
extensión, en la ciudad. Con ello asegurariamos el tránsito hacia un imaginario capaz de dar cuenta de la experiencia completa de regiones que hoy no se ven sino como extrañas o ajenas; a lo más, complementarias de una visión arquetípica de Sevilla.

La estrategia sobre el Sur mide y comprueba, experimenta otros usos para estos grandes canales del flujo y la velocidad, poniéndolos en relación con otras piezas significadas por la representación de la arquitectura, reciclándolas: cuarteles, hospitales, fábricas eléctricas, exclusas... heterotopias que han significado históricamente la disponibilidad de este territorio del sur. Entre ellas, midiendo los intersticios, sus frentes positivados, el proyecto encuentra sus lógicas, sus proyecciones compensatorias hacia una ciudad repleta de nuevos escenarios donde anidar la vida.

Y en esta representación, la Sevilla actual: metrópolis policéntrica cuya nueva naturaleza se basa en una componente territorial indiscutible que se desvela en la opción de un proyecto metropolitano, en la apuesta por una comunidad de intereses en la que cada núcleo ha de encontrar su papel -superando la autosuficiencia como gesto de compromiso- y en la voluntad de transformar una estructura de ocupación de un territorio que da origen a una lógica infraestructural perversa.

Con los trabajos para la Oficina del Plan de Sevilla surgió la posibilidad de abordar las grandes bandas del entorno metropolitano de Sevilla guiados, no ya por un afán continuista de la ciudad existente, sino por la consideración de territorialidad que los nuevos signos de ocupación en este punto del valle del Guadalquivir planteaban. Y de entre ellas y desde su posición relativa, el Sur apareció como una extensa región, tan desconocida como anhelada para el conjunto de los ciudadanos.

Nombres como Aljarafe, Tablada, Puerto de Sevilla, Polígono Sur, HYTASA, Guadaira o Alcores, pertenecian al imaginario de la ciudad. Pero en un segundo plano, como episodios siempre aislados, como voces incapaces de hilvanar una mínima narración con todos estos fragmentos inconexos. La lógica determinante de la ciudad, tan dependiente de su centro, los había dejado de lado y actuaciones acaecidas en estos últimos años habian conducido a situaciones altamente anómalas y conflictivas en el ámbito social y, consecuentemente, urbano. Barrios de habitación muy diferenciados, tan marginados como deseados, conforman el tapiz residencial de la zona. Una historia urbana muy reciente, a veces dramática, que a pesar de hacer uso de modelos de crecimiento de muy aceptables estándares y arquitecturas, ha producido fracturas nunca recompuestas en este sector de la ciudad debido a politicas sociales fallidas, consolidando embolsamientos de usos y grupos sociales muy dispares y de compleja integración.

\section{La acción generadora: bandas de actividad para la cohesión}

Se ha tratado, con esta aproximación al Sur, de hilvanar pequeños relatos que nos conecten con la ciudad y su área metropolitana. Una visión descentrada que descubre otras polaridades -el Guadaira: porque Sevilla tiene dos ríos- e inventa lugares en un tejido de estructura débil, dispar e incompleta. Ello, con la intención de disolver las condiciones heredadas para construir un conjunto de relaciones potenciadoras de la vida del sitio que posibilite la incor-

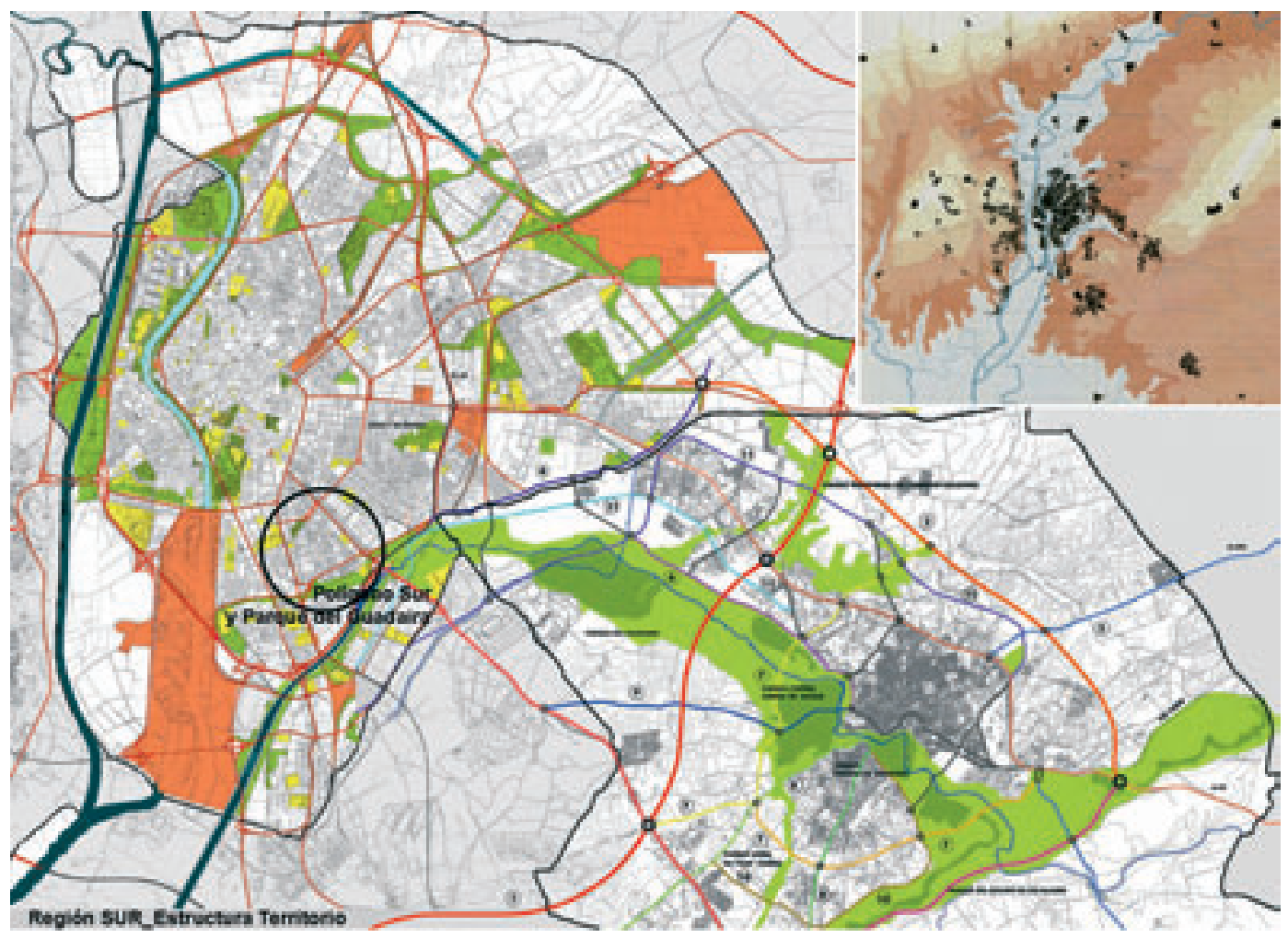

El sector sur en el área metropolitana de Sevilla. Fuente: FACTOR-IA 
poración de nuevos flujos de personas y actividades en una zona marcada por su marginalidad en el conjunto de la ciudad.

La existencia de unas fronteras insalvables en los bordes del Polígono Sur poco ayudaba a garantizar dicha cohesión. Nos encontramos así, en su límite occidental, el trazado en trinchera del ferrocarril que lo separa de la barriada de Bami -utilizando el tren como elemento disuasorio y de protección, con su doble valla espinada-; o los muros del área industrial de HYTASA, en su borde oriental, y del club social de Pineda al sur, que actuaban como barreras del Polígono Sur.

El punto de partida ha sido la revisión de esas fronteras, no con la idea de articular áreas o encontrar los resquicios para conectar el barrio, sino para incorporar actividades potencialmente favorables que guiaran la naturaleza de la intervención. Se visualizó así, una estructura de organización de rango superior llamada a dotar de sentido común -como multiplicidad-al conjunto de realidades complejas del sector, incorporándolas a una actualidad nueva que se plantea desde el horizonte metropolitano. Es la matriz verde -ecológica y patrimonial- del sur del área metropolitana y, en ella, el dilatado parque lineal del Guadaira como dispositivo cohesionador y dinamizador que utiliza como argumento el agua para su configuración, singularizando los diversos ámbitos que encuentra a su paso. Éste se constituye por los solapes que produce con las distintas zonas, definiendo y caracterizando la figura y la vida nueva del sur.

Así, poner en carga este espacio pasa por configurar en sus bordes nuevas bandas de actividad y atracción de nuevos flujos de población hacia el sector que, transversalmente, se superponen al parque lineal segmentándolo en un conjunto de episodios diferenciados. El resultado ha sido un mapa hecho con tejidos que se solapan, un soporte de comprensión y acción. Éstas son:

\section{Dársena del Guadalquivir}

Banda que reordena los espacios verdes, actividades culturales, educacionales y de ocio y elementos de la ciudad que van asociados al río. Se registra con ella la ciudad histórica de norte a sur, al tiempo que se convierte en una pieza vital para la relación con el área metropolitana, produciendo de nuevo el encuentro entre el viejo cauce del Guadaira y el Guadalquivir, en un sitio caracterizado por la extensión de las vistas y el atractivo de las actividades portuarias asociadas a la margen derecha del río. Alli se prevé localizar un gran espacio escénico, pequeñas instalaciones asociadas a la actividad docente, al ocio y al transporte fluvial y un conjunto de viviendas que completan las dotaciones de esta zona.

\section{Corredor ferroviario y Área de Ciencias de la Salud}

La necesaria revisión de los límites que se han establecido en los últimos años en el contorno de las 3000 viviendas del Polígono Sur señala especialmente al ámbito del corredor ferroviario como la barrera más infranqueable que acentúa la segregación y marginación de aquéllas en relación con la ciudad. Así pues, el soterramiento de la línea del ferrocarril hasta pasado el Parque del Guadaira supone una modificación sustancial de todo este sector, posibilitando tanto la transversalidad y conexión entre estos sectores como la de la ciudad con la población de la zona sur del área metropolitana.

Lo que permite la estructuración de una nueva banda de actividad de extraordinaria capacidad por su situación y accesibilidad. Que en esta banda se reúnan numerosos centros sanitarios e instalaciones dedicadas al conjunto de las prácticas hospitalarias de los estudiantes hace que podamos hablar de un área o campus de Ciencias de la Salud que gestionaría dicha actividad, resolviendo las carencias actuales e incorporando un programa de habitación de alquiler de interés público y social de apoyo a familiares de enfermos, estudiantes o al personal sanitario.
La intención es construir un conjunto de relaciones potenciadoras de la vida del sitio que posibilite la incorporación de nuevos flujos de personas y actividades

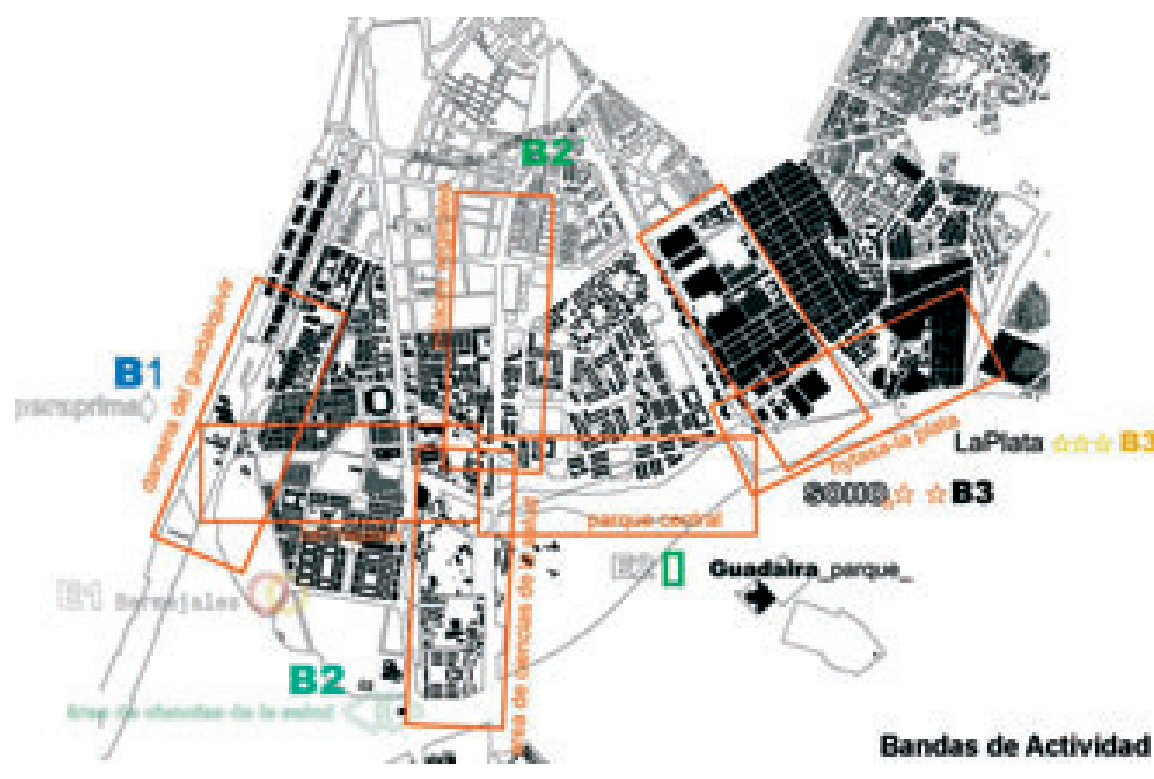




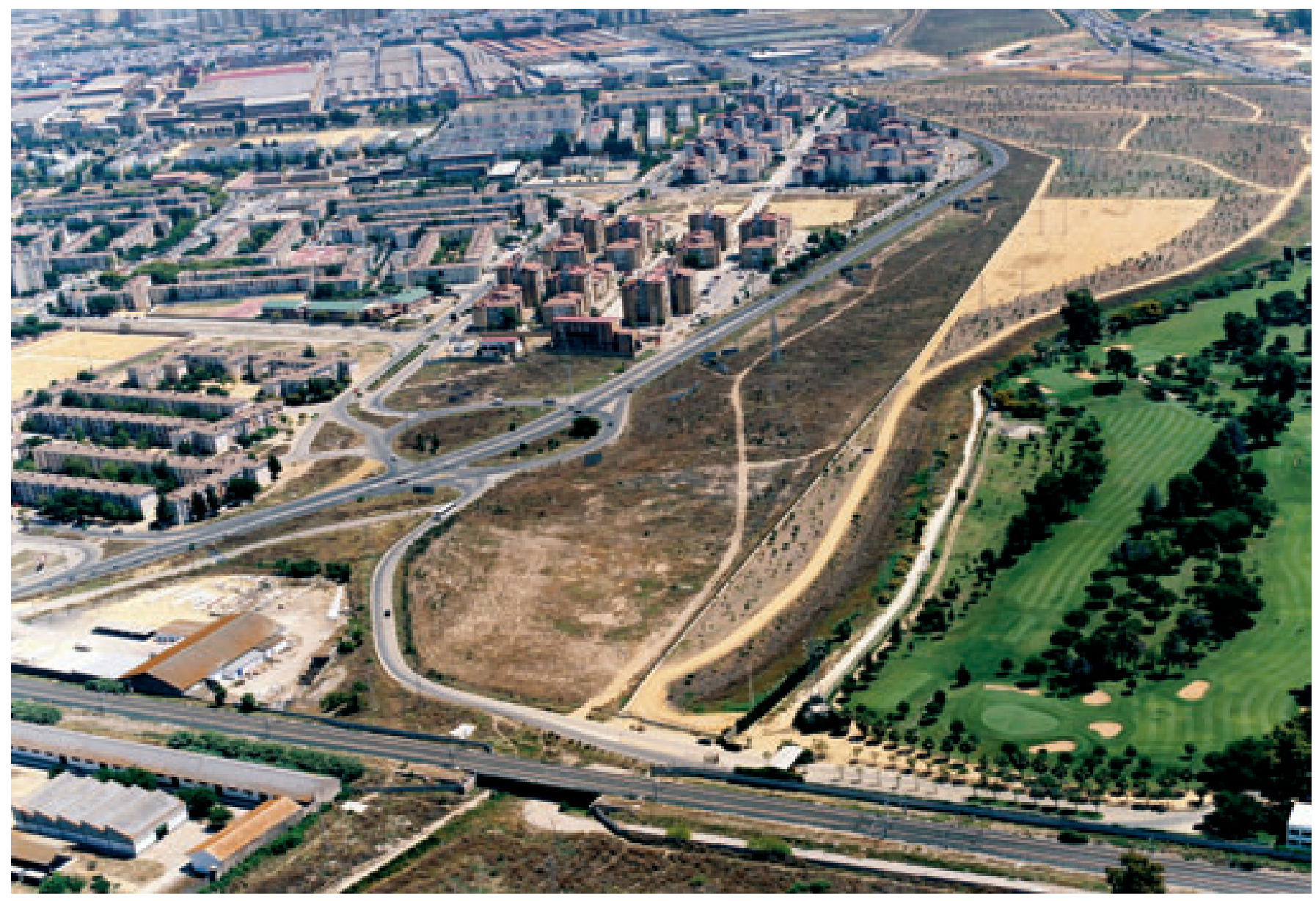

Encuentro del parque y la barriada de Las Vegas del Polígono Sur de Sevilla. Fuente: Diario de Sevilla

\section{Pequeño SOHO}

El objetivo fundamental de permeabilizar los límites de la barriada, en su borde oriental en contacto con el polígono industrial, es del todo compatible con la presencia y puesta en valor de un importante patrimonio etnológico y arquitectónico industrial contemporáneo: invirtiendo polaridades, introduciendo nuevas actividades más híbridas, con la intención de atraer a cortes de población más dinámicos y, al tiempo, potenciar conexiones transversales de una parte a otra de ciudad en la estrategia de cohesión social planteada.

Podrian aparecer, ubicándose en estas instalaciones recicladas, nuevos usos de interés y escala metropolitana. Hablamos de las demandadas Escuelas de Flamenco o del Circo, que vendrían acompañadas por la gestión concertada de las otras naves originarias existentes, con fórmulas de alquiler modular como espacios de desarrollo artístico de la ciudad para potenciar la creación plástica y su mercado, destinándolos a galeristas, talleres de experimentación, sets de rodaje y audio, grupos independientes de música, teatro y expresión corporal, estudios profesionales, etc.

Si las bandas de actividad que lo abrazan pretenden su despliegue hacia la ciudad, en su salida hacia el sur es el propio Parque sobre el antiguo cauce del Guadaira, como parque equipado con dotaciones tanto municipales como metropolitanas, quien asume el compromiso de dilatar este fondo a derecha e izquierda, enganchando el sector en la matriz verde metropolitana. El diseño del parque, en su encuentro con el conjunto edificado de Las Vegas y como parte de las intervenciones a desarrollar de rehabilitación y mejora social, dispone de un área acotada de tratamiento y mantenimiento gestionado por las distintas asociaciones y comunidades de vecinos existentes: plantaciones de chopos, de plantas aromáticas o flores tradicionales, áreas de juego para niños y mayores, etc.

Con esas bandas como referencias, los límites se revisan y hacen relativos. Con estas actividades, la participación ciudadana encuentra en la zona de intervención otras pautas de comportamiento.

\section{La gestión de un proyecto}

Nos detendremos ahora en este ensayo que recoge y sintetiza lo que aqui se habla: la construcción de un parque metropolitano, de cerca de 65 hectáreas y 3000 metros de longitud, que recorre la banda sur de Sevilla. Si el episodio último de esta acción está por llegar, con la puesta en uso por los ciudadanos, toda una serie de etapas previas nos sirven de guía para explicitar el modo de hacer y los instrumentos proyectuales volcados sobre esta realidad, atendiendo tanto a la recuperación ambiental del entorno del antiguo cauce del río, mediante la restauración hidrológica y reforestación, como a la importancia de este espacio público para procurar la cohesión urbana, social y cultural del sector del Polígono Sur con el resto de la ciudad. 
Se trata de un área irregular, con forma de banda alargada y sinuosa, que recorre áreas muy diferenciadas de la ciudad. En estas condiciones va a ser la caracterización hidrográfica del sitio, el agua hoy más que nunca, uno de los grandes dispositivos de cohesión entre espacios de naturaleza y desarrollos diversos, al tiempo que la gran referencia territorial en el marco del área metropolitana. En especial el río Guadaira, que aparece recorriendo el sur de la ciudad de este a oeste, en su doble expresión de cauce viejo y artificial, como un continuo de relación marcado por su carácter verde -asociado al esparcimiento, al ocio y al deporte en sus diversos grados de participación ciudadana- y agrario -base para la recuperación de una memoria asociada al sitio-, haciéndolo singular.

La definición y carácter de los episodios que lo segmentan se enuncian a continuación:

\section{(I-II). El agua, la habitación, el deporte}

La zona occidental es el ámbito de los tránsitos urbanos del parque, recorrido desde el paso del corredor ferroviario hasta la cabecera de la dársena por un vial de tráfico rodado, es donde la banda se hace más estrecha y da cuenta con mayor concreción de situaciones más diversas.

Una estrecha franja verde por la que discurre la vía del Guadaira y en la que aparece el agua formando parte de las nuevas escenas propuestas. Que se sitúe entre el campus universitario de Reina Mercedes y el propuesto de Ciencias de la Salud convierte este tramo del Parque del Guadaira en un importante elemento de conexión entre ambos.

\section{(II-III). Ocupaciones}

La oriental, banda ancha que da frente al Polígono Sur, descubre escenas, elementos de alto valor patrimonial para los vecinos -Molino de la Torre Blanca- y actividades asociadas al esparcimiento y el tiempo libre de carácter sectorial y general. Es la zona de transferencias con el barrio y la ciudad, donde pueden ocurrir muchas cosas: en ella se recrea el antiguo cauce con la zona lagunar y distintos ámbitos de protección, aparecen las

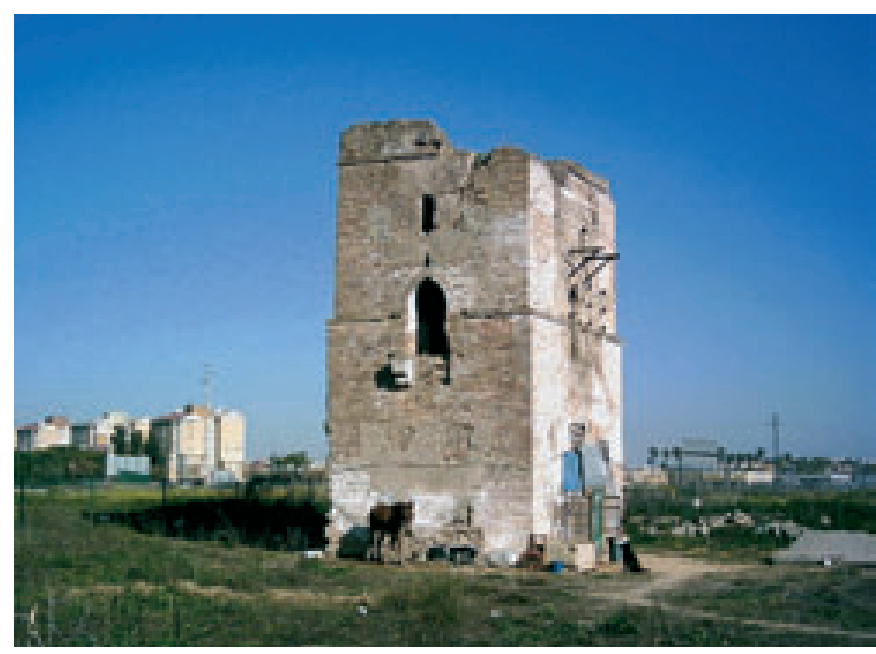

Imagen de la Torre Blanca. Fuente: FACTOR-IA áreas de frutales y huertos de gestión vecinal, se significa la Torre encontrada y su entorno como seña de identidad, se lanza el paso sobre la autovía para conectarlo con el parque del Guadaira vivo, además de plantear instalaciones deportivas, de baño o usos más singulares.

Como objeto de deseo para muchos y excusa para la revisión del sector sur de la ciudad, la actuación propone una historia distinta que busca implicar al vecino y usuario en el parque, hasta hacerlo suyo para mejorar su mantenimiento, pero sobre todo quiere ser el gran argumento a través del cual descubrir esos territorios actuales en los que entendemos puede haber una habitabilidad distinta y casi necesaria, complementaria en cualquier caso, a otra manera de entender la ciudad. Tal vez porque, como plantea Germán Cano, "tenemos la necesidad de cultivar y construir a tientas una nueva habitabilidad no depredadora respecto al entorno y la alteridad" (CANO, 2003).

\section{El efecto resemantizador}

La actuación habria que enmarcarla dentro de una serie de intervenciones significativas, localizadas en el Polígono Sur de Sevilla -en la barriada Martínez Montañés, más conocida popularmente con el nombre de Las Vegas por su marginalidad y desestructuración social y urbana- y encaminadas a corregir sustancialmente la imagen que de la barriada tiene el conjunto de la población reconociendo nuevas identidades. El objetivo es superar el deterioro social y arquitectónico ocasionado por la ocupación de la misma por grupos marginales, que en muchos casos han sustituido a la población inicial, así como la inadecuación de unos modelos habitacionales con las formas de vida de sus pobladores que ha dado como resultado el abandono de los espacios de la calle y el de las propias viviendas. Algo que se extiende, también, a los modos de vida y comportamientos sociales, a los nombres y significados simbólicos de los lugares, provocando iguales fracturas entre comunidades vecinales. Hoy, en cualquier territorio o cultura, y muy especialmente en estos ámbitos, las técnicas y agentes que intervienen en estos procesos de transformación precisan de otros procedimientos capaces de registrar toda la complejidad, interactuando entre ellos, dando su papel a los individuos y perfilando un nuevo paisaje cultural diferenciado para cada situación.

Es lo que ocurre con el Polígono Sur de Sevilla: un lugar cargado de significados impuestos, de prejuicios heredados, de sensaciones extremas. Pero como otros tantos lugares contemporáneos, ni tan terrible como para el extraño que lo evita por inseguro, ni tan atractivo como para el que se reconoce en los márgenes de lo reglamentado o lo registra como objeto de goce artístico (identidad asociada al flamenco). Sí podremos decir, sin temor a equivocarnos, que es un lugar extraordinariamente serio y complejo, ambiguo y actual; un sitio donde llegar a encontrarnos con la realidad del presente urbano de nuestras ciudades, una realidad en la que estamos obligados a ensayar modos nuevos de gestión y forma de sus espacios singulares. 


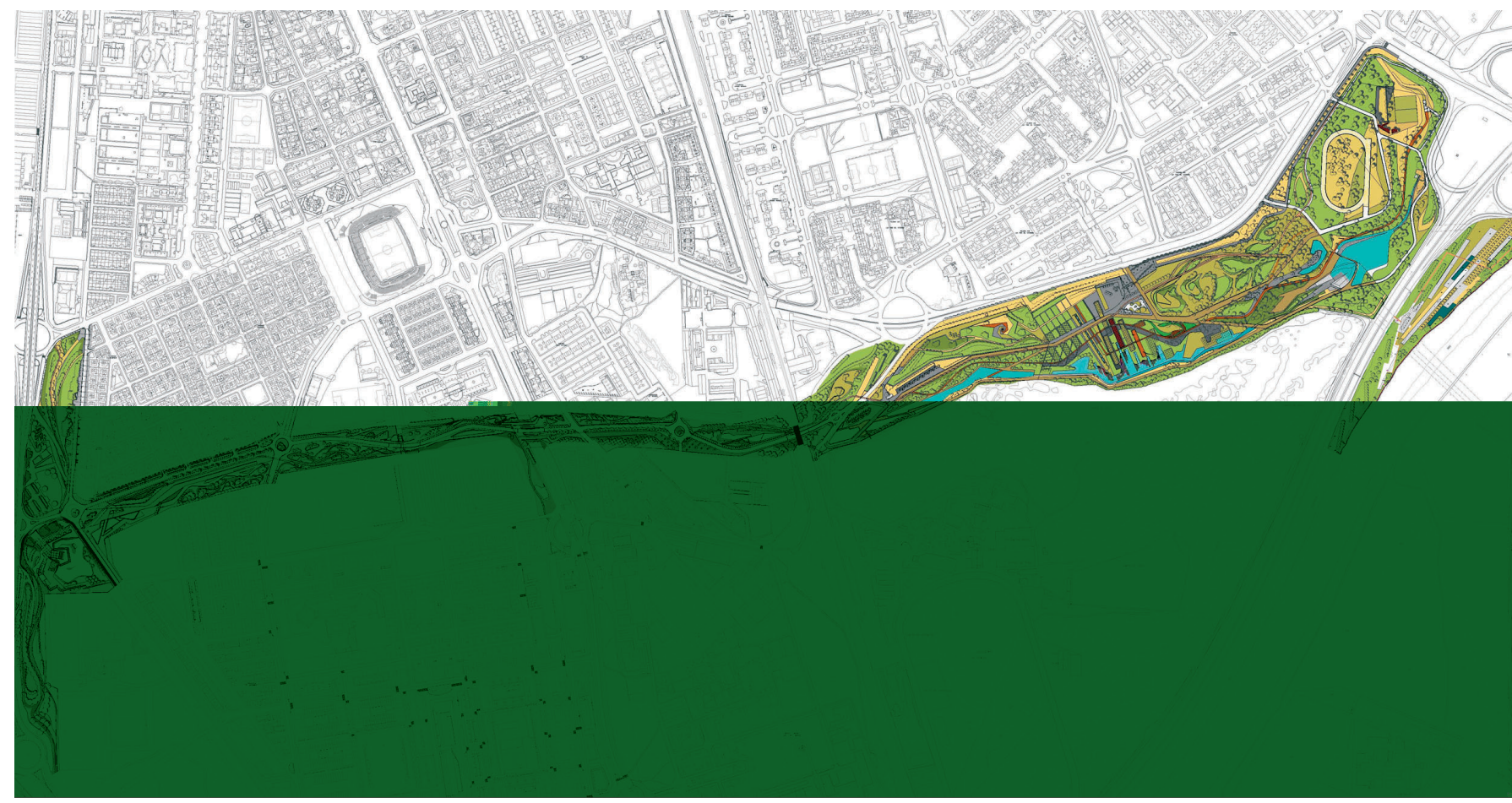

Plano Base del Parque del Guadaira. Ordenación. Fuente: FACTOR-IA

\section{FICHA TÉCNICA}

\section{Proyecto}

Parque sobre el Antiguo Cauce del Río Guadaira

\section{Ubicación}

Sevilla

\section{Promotores}

Confederación Hidrográfica del Guadalquivir

Ayuntamiento de Sevilla

\section{Autores}

UTE FACTOR-IA / UG21

\section{Consultores}

Inma Jansana, paisajista

Iván Nieto, biólogo

Pablo Ramiro, ingeniero forestal

Arturo Ruiz, arqueólogo

Javier Aldarias, artista

\section{Superficie}

65 hectáreas

\section{Inicio construcción}

Febrero 2007

\section{Presupuesto obra}

21 millones de euros
Para la administración local, y para la ciudad en general, el Polígono Sur es considerado como Área de Gestión Integral en el documento de Estrategias del PGOU de Sevilla, lo que significa que es un barrio en crisis en el que el planeamiento puede colaborar de manera importante a la cohesión social y urbana.

Así las cosas, cualquier acción proyectual pasaría por desvelar nuevas tematizaciones urbanas, interpretándolas y midiendo su relevancia dentro de la génesis de un futuro entorno virtual que subsume las estructuras y conformación de la artificialidad. En este sentido, desde la perspectiva que introduce el Plan Integral para el Polígono Sur en razón a su cohesión social con el resto de la ciudad, se ve la conveniencia de propiciar intervenciones significativas que corrijan y modifiquen la imagen que del Polígono se tiene por el conjunto de los ciudadanos y, con ellas, activar la participación en relación con sus referentes más próximos. Nos vale como ejemplo el valor añadido que los vecinos de la barriada Martínez Montañés otorgan a los restos del molino de la Torre Blanca.

Aparecen como oportunidades claras para este fin, entre otras de carácter social, las relacionadas con actuaciones sobre la propia materialidad de la barriada, tanto a nivel urbanístico como arquitectónico: singularmente, la incorporación al nuevo parque de dotaciones con nuevos usos y actividades participativas (algunas de posible autorregulación) para los vecinos del barrio, y de otras áreas de la ciudad, o la ya citada sobre la Torre Blanca, como referente y seña de identidad vecinal.

Este efecto resemantizador se extendería como estrategia a todo el parque como instrumento configurador de un nuevo paisaje urbano para Sevilla. 


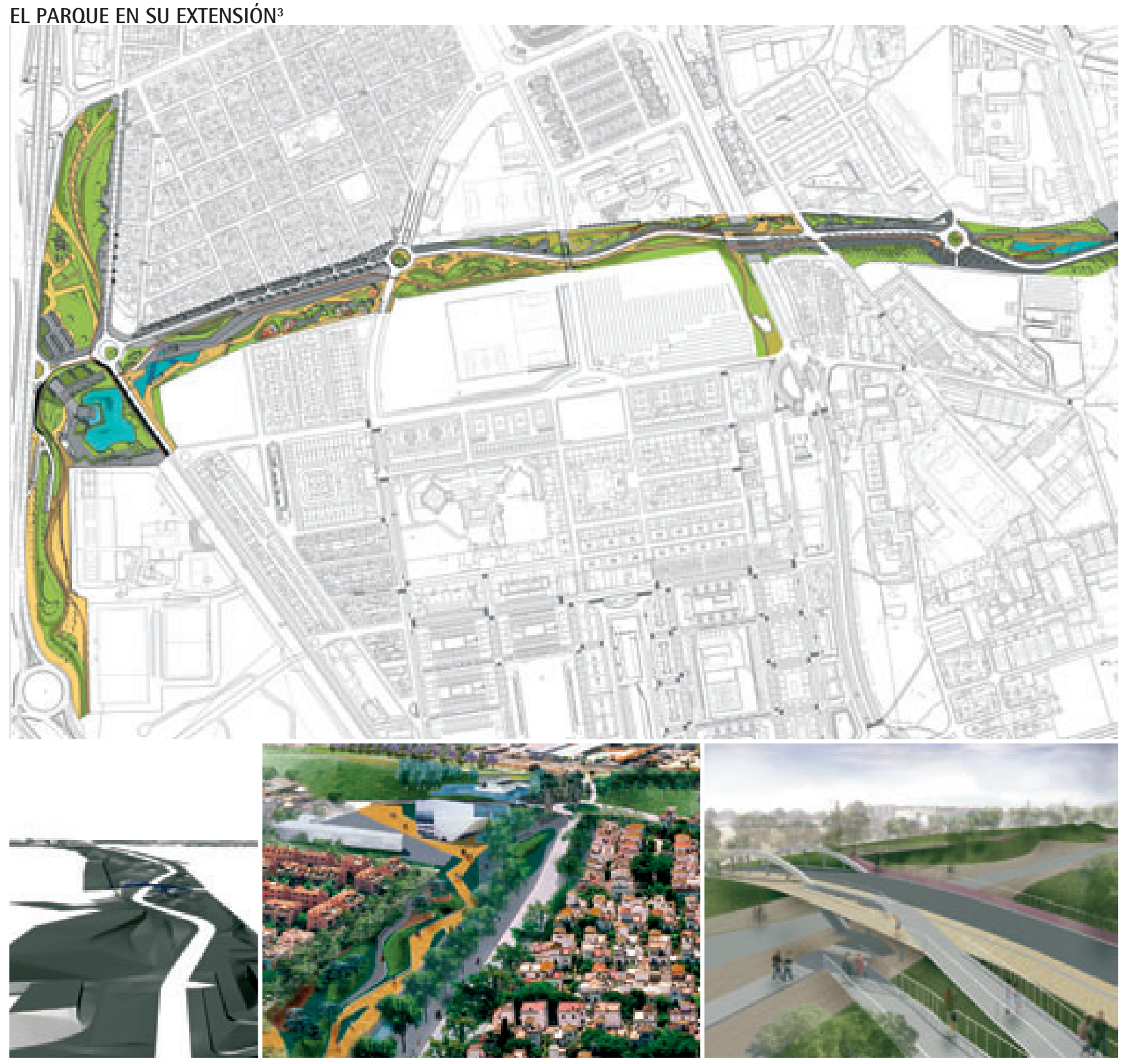

Sector occidental del Parque. Borde Avenida de la Raza (arriba). Infografía del parque desde su cabecera occidental (abajo izquierda). Cabecera occidental, entre los barrios de Heliópolis y Bermejales (abajo centro). Paso de la avenida de Holanda (abajo derecha). Fuente: FACTOR-IA

Se ve la conveniencia de propiciar intervenciones significativas que corrijan y modifiquen la imagen que del Polígono se tiene por el conjunto

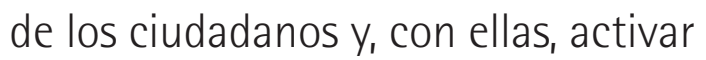
la participación en relación con sus referentes más próximos 


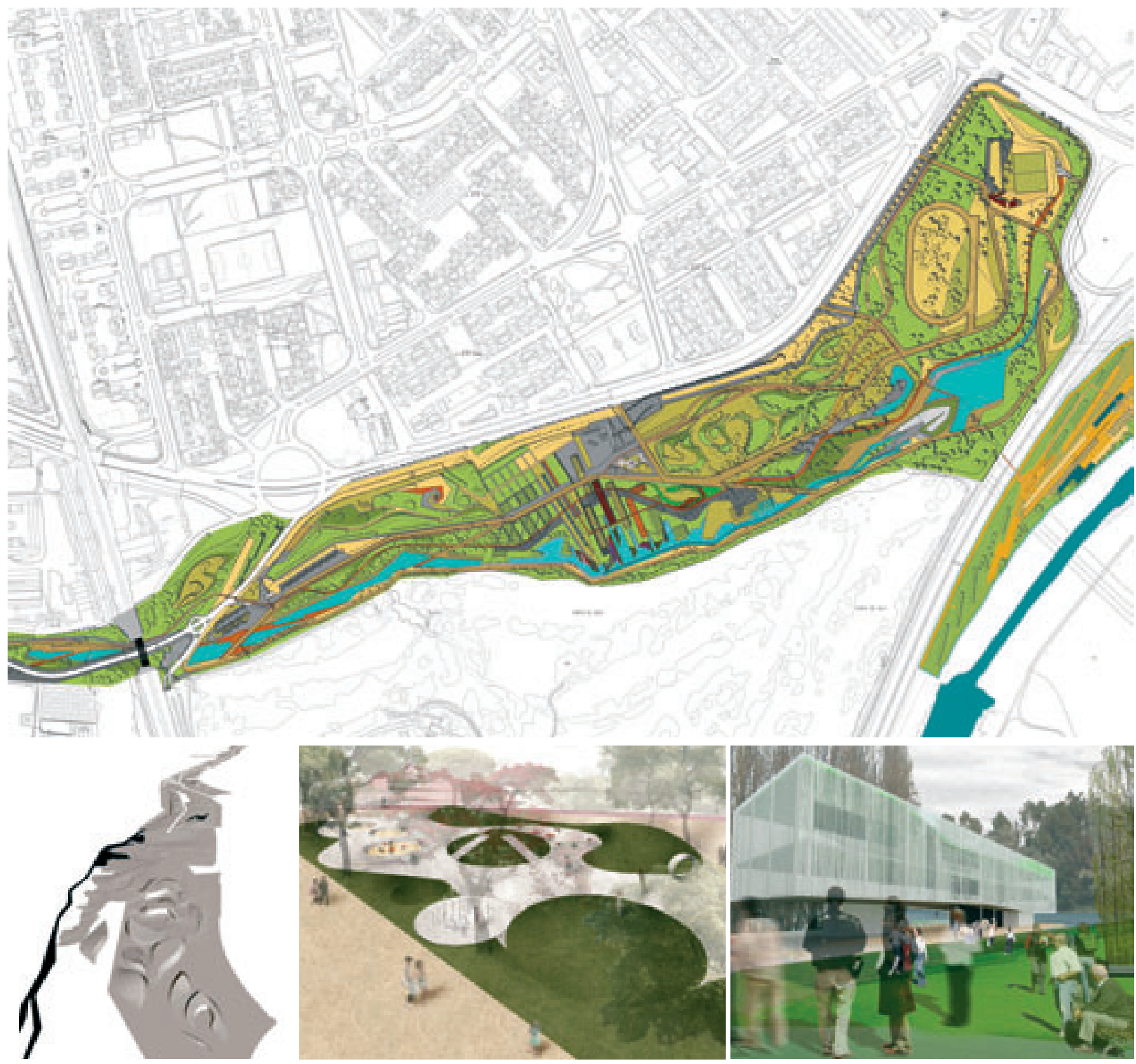

Sector oriental del parque. Borde carretera de Utrera (arriba). Infografía desde su cabecera oriental (abajo izquierda). Parque infantil (abajo centro). Parque Central, entre la barriada Martínez Montañés y el club Pineda (abajo derecha). Fuente: FACTOR-IA

\section{Notas}

El Foro Barriadas-Sevilla, impulsado por la COPyT y comisariado por José Ramón Moreno Pérez y Félix de la Iglesia Salgado, sirve de soporte para la reflexión continuada sobre las barriadas en nuestras ciudades. Articulado en torno a 5 lineas de trabajo (Sociología, Antropología, Urbanismo, Arte y Arquitectura), engloba múltiples aspectos presentes en la problemática de estos ámbitos urbanos, posibilitando con distintas entradas, otros enfoques para las actuaciones a desarrollar en ellas. ${ }^{2}$ El proyecto patrimonial ha sido formulado por el Máster en Arquitectura y Patrimonio Histórico a lo largo de sus 12 ediciones en el seno del IAPH.

${ }^{3}$ La documentación completa del Proyecto del Parque sobre el antiguo cauce del Guadaira puede consultarse en www.factor-ia.com, http://www.youtube. com/watch?v=22XMiA36Rp8 y en http://www.laciudadviva.org/opencms/04_ experiencias/index.html?pagina $=2 \#$

Ésta forma parte de la investigación, objeto del presente artículo, que se ha desarrollado en el seno de FACTOR-IA desde que en el año 2001 se iniciaran los trabajos del actual PGOU de Sevilla hasta la fecha, en fase de construcción, siendo contrastada con asociaciones de vecinos y administraciones implicadas.

FACTOR-IA es: Félix de la Iglesia, Miguel Ángel Rojas, José Antonio Ruiz, María Dolores López, Rocío Vázquez, Sergio Viels y Antonio Calzado.

\section{Bibliografía}

CACCIARI, M. (2000) Geo-filosofía de Europa. Madrid: Aldebarán, 2000 CANO, G. (2003) Cómo habitar en tiempos volcánicos. En SLOTERDIJK, P. Experimentos con uno mismo. Valencia: Pre-textos, 2003

DELGADO, M. (2003) La No-Ciudad como ciudad absoluta. Revista Sileno, nº 14-15, 2003, p. 130

GADAMER, H.G. (1984) Verdad y método. Salamanca: Sígueme, 1984, p. 45 MORENO, J. R.; DE LA IGLESIA, F. (2006) Nuevos Centros Urbanos. Foro Barriadas. Presentación del encuentro www.forobarriadas.es D.G. de Arquitectura y Vivienda. Junta de Andalucia. Sevilla, 2006

SILVA, A. (2005) Imaginarios urbanos: hecho público. Exposición Seminariotaller UNIA. Sevilla, 2005 